\title{
Dextromethorphan abuse
}

A wide range of drugs is being abused by teenagers across the world, and over the years, they seem to have made the discovery that they could get "high" by taking over-the-counter medicines containing dextromethorphan (DXM). Cases of recreational use of DXM [1] and its sideeffects [2] have been reported in other countries. The following case histories are presented to emphasise the main clinical features and the management of dextromethorphan abuse among Sri Lankan youths.

A 19-year old male, who had been abusing Corex-D for the last four years presented with elevated mood, visual hallucinations and a recent risk taking life-style. He also had experienced dissociative states and depersonalisation. A 17-year old schoolboy with an unremarkable past history, presented with undue irritability, social withdrawal and declining school performance over the last 4-5 months. A previously stable 16-year old schoolboy, presented with social withdrawal, irritability, paranoid and grandiose delusions for the last 2 months. He had been taking Corex$\mathrm{D}$, for 4-5 months. A male in his thirties presented with paranoid delusions and auditory hallucinations of one month's duration. A male in his twenties had become socially withdrawn, paranoid and mute over a period of 45 days. He had been abusing Corex-D, daily for the last 6-8 months.

All 5 patients had been abusing Corex-D in amounts exceeding $120 \mathrm{mg}$ daily. They made a good recovery after stopping the substance, and with adequate doses of antipsychotics. We also used behaviour therapy programmes to change their life-styles in positive ways and included the family in the management. Educational programmes were used to emphasise the dangers of misuse of substances, including Corex-D.
Dextromethorphan (DXM) is an opiate agonist $[1,3]$ and the $\mathrm{D}$-isomer of levorphanol $[1,3,4]$. Some ingest 250 to $1500 \mathrm{mg}$ in a single dose. The recommended therapeutic dose is 10 to $20 \mathrm{mg}$ every 4 hours or $30 \mathrm{mg}$ every 6 to 8 hours [5]. In doses above $120 \mathrm{mg}$, the effects of DXM are similar to those of phencyclidine or ketamine [3]. These include visual hallucinations, dissociative anaesthesia and depersonalisation, stupor, distortion of motion or speech, and agitation [3]. Our case histories show most of these symptoms. Chronic ingestion of large doses of DXM can cause psychotic states. A large dose is defined as 5 to 10 times the dose recommended for control of annoying nonproductive cough [3]. DXM is abused as a group activity or alone. The misuse of DXM in Sri Lanka may increase, as the drug is legal, relatively easy to obtain, inexpensive, and because of its less stigmatising nature and the low risk perceived by abusers and relatives. Parents should be made aware of the drug's potential for abuse and the possibility that DXM abuse can act as a gateway for abuse of more dangerous drugs.

\section{References}

1. Murray S, Brewerton T. Abuse of over-the-counter dextromethorphan by teenagers. South Medical Journal 1993; 86: 1151-3.

2. Ziaee V, Akbari HE, Hoshmand A, Amini H, Kebriaeizadeh A, Saman K. Side effects of dextromethorphan abuse, a case series. Addictive Behaviors 2005; 30: 1607-13.

3. Schwartz RH. Adolescent abuse of dextromethorphan. Clinical Paediatrics 2005; 44: 565-8. 
4. McFee RB, Mofenson HC, Caraccio TR, Mineola NY. Dextromethorphan: another "ecstacy" ? Archives of Family Medicine 2000; 9: 123.
5. Intelligence Bulletin: DXM(Dextromethorphan). National Drug Information Center. Office of Policy and Interagency Affairs United States Department of Justice. Washington, D.C, 2004.

\section{A Hapangama and K A L A Kuruppuarachchi}

Department of Psychiatry, Faculty of Medicine, University of Kelaniya, Ragama, Sri Lanka.

Correspondence: KALAK, e-mail <lalithkuruppu@lycos.com>. Competing interests: none declared. Received 7 September 2007 and revised version accepted 11 January 2008. 